Rabaska

Revue d'ethnologie de l'Amérique française

\title{
Chaire de recherche du Canada en patrimoine ethnologique
}

\section{Laurier Turgeon}

Volume 6, 2008

URI : https://id.erudit.org/iderudit/000121ar

DOI : https://doi.org/10.7202/000121ar

Aller au sommaire du numéro

Éditeur(s)

Société québécoise d'ethnologie

ISSN

1703-7433 (imprimé)

1916-7350 (numérique)

Découvrir la revue

Citer ce document

Turgeon, L. (2008). Chaire de recherche du Canada en patrimoine ethnologique. Rabaska, 6, 240-242. https://doi.org/10.7202/000121ar d'utilisation que vous pouvez consulter en ligne.

https://apropos.erudit.org/fr/usagers/politique-dutilisation/ 


\section{QUÉBEC}

\section{Chaire de recherche du Canada en patrimoine ethnologique}

Pavillon Jean-Charles-Bonenfant

Université Laval

Québec (Québec)

G1K 7P4
Téléphone : (418) 656-2131, poste 13571

Courriel : Laurier.Turgeon@hst.ulaval.ca Toile : www.patrimoine-immateriel.ulaval.ca

L'année 2007-2008 fut très riche pour la Chaire de recherche du Canada en patrimoine ethnologique, tant dans le domaine de la recherche fondamentale que de la recherche appliquée et de la formation des étudiants.

\section{Recherche fondamentale}

Le volet recherche fondamentale de la Chaire fut marqué par la publication de deux livres. Le premier, intitulé Objets et mémoires, coédité par les Éditions de la Maison des sciences de l'Homme (Paris) et les Presses de l'Université Laval (Québec), représente une contribution importante pour l'étude du rapport entre les objets matériels et la mémoire sociale, le patrimoine matériel et le patrimoine immatériel. L'ouvrage regroupe des contributions des meilleurs spécialistes internationaux de la question, entre autres : James Clifford (University of California, Santa Cruz), Janet Hoskins (University of Southern California), Bruno Latour (Sciences Politiques, Paris), Jacques Hainard (Musée d'ethnographie de Genève), Dominique Poulot (Université de Paris I Panthéon-Sorbonne, Institut universitaire de France). Les auteurs ont été invités à lancer l'ouvrage au Musée du Quai Branly à Paris ainsi qu'au Musée d'ethnographie de Genève. Il a déjà reçu plusieurs compte rendus très favorables dans les meilleures revues d'ethnologie (Gradhiva, Terrain, Ethnologie française, Anthropologie et sociétés).

Le deuxième livre porte sur les relations de voyage françaises au Canada du Xvi ${ }^{\mathrm{e}}$ au Xx ${ }^{\mathrm{e}}$ siècle. Coédité avec les Éditions du CTHS (Paris) et les Presses de l'Université Laval (Québec), cet ouvrage démontre que les relations de voyage représentent une importante source ethnographique qui éclaire les échanges interculturels entre Français et Amérindiens et la construction des «patrimoines métissés ».

\section{Recherche appliquée}

Le volet recherche appliquée a permis la réalisation de deux projets : une base de données électronique accessible sur la toile du patrimoine culturel immatériel du Québec et une encyclopédie multimédia du patrimoine culturel de l'Amérique française. La base de données recense les principaux éléments 
du patrimoine culturel immatériel du Québec, tout en tenant compte des emprunts faits aux autres cultures.

L'usage des technologies numériques utilisées et les méthodologies développées ont permis à la Chaire de révolutionner les modes de sauvegarde et de mise en valeur du patrimoine culturel immatériel et de se hausser au rang de leader mondial dans le domaine. La constitution d'une banque de données électronique, sur la toile, permet de conserver du texte, des images, et des enregistrements sonores et audio-visuels en ligne, puis de les rendre accessibles au grand public à tout moment. La base de données de la Chaire est de plus en plus citée par l'UNESCO et a déjà suscité des collaborations avec la Belgique, la France, la Suisse et la Chine. Laurier Turgeon a d'ailleurs été invité à être membre de la délégation canadienne, constituée par le Réseau canadien d'information sur le patrimoine, pour présenter l'expertise canadienne en matière de patrimoine culturel immatériel en Chine du $1^{\mathrm{er}}$ au 4 août 2008.

Le volet recherche appliquée a également vu le lancement de l'Encyclopédie du patrimoine culturel de l'Amérique française qui est à la fois un lieu de promotion de nouvelles connaissances et un outil efficace de communication multimédia du patrimoine de l'Amérique française. De même, l'Encyclopédie du patrimoine culturel de l'Amérique française vient d'être citée comme un modèle en matière d'encyclopédies électroniques en patrimoine dans le dernier bulletin d'information de la section du patrimoine de l'UNESCO. Ce bulletin est distribué dans 180 pays (whc.unesco.org).

\section{Collaboration}

Les collaborations locales et régionales de la Chaire sont une priorité et font partie intégrante de son fonctionnement, étant donné que la base de données IREPI a pour objectif principal d'impliquer ces communautés, locales et régionales, dans l'inventorisation et ainsi la valorisation du patrimoine culturel immatériel. La participation de la population et des institutions fait partie intégrante de la pratique même de l'inventaire. Les étudiants sur le terrain ont l'obligation d'associer les populations locales à l'inventaire et d'envisager des projets de mise en valeur de ce patrimoine par des actions culturelles : expositions, conférences, événements médiatiques, circuits touristiques, colloques et, bien sûr, l'usage de la base de données même qui est accessible sur la toile. Le projet a conduit à la mise en place d'infrastructures plus permanentes, comme le Musée de la mémoire vivante à Saint-Jean-Port-Joli qui a été inauguré à la fin de juin 2008.

Depuis deux ans, la Chaire collabore avec des organismes régionaux, notamment le Musée québécois de culture populaire, le Musée de la mémoire 
vivante, la Société québécoise d'ethnologie, et des organismes internationaux : ministère de la Culture de la France, Musée panafricain de la musique, UNESCO, ministère de la Culture du Québec, ministère des Affaires municipales et des régions du Québec, Parcs Canada. Les collaborations sont intenses avec les collègues de l'Université Laval. Par exemple, le titulaire a monté un programme de maîtrise en patrimoine et mémoire à l'Université d'État d'Haïti (UÉH) avec Bogumil Koss, Habib Saidi, Réginald Auger, Henri Dorion, tous de l'Université Laval, ainsi qu'avec les enseignants d'Haïti. Ajoutons que le titulaire a été invité à siéger sur des jurys de plusieurs thèses, au Canada et à l'étranger (France, Belgique), au comité scientifique de l'Institut d'études canadiennes de l'Université d'Ottawa et, à titre de professeur pendant un mois, à l'Université de Paris I Panthéon-Sorbonne.

Des collaborations avec des chercheurs étrangers de renom se sont développées aussi par l'organisation à Québec de grands congrès internationaux : le congrès annuel de l'American Folklore Society en octobre 2007, le $133^{\mathrm{e}}$ congrès du Comité des travaux historiques et scientifiques de la France, la 16 ${ }^{\mathrm{e}}$ assemblée générale d'Icomos en octobre 2008 à Québec.

La Chaire a permis d'encadrer deux boursiers post-doctoraux, douze étudiants de doctorat et douze étudiants de maîtrise. Grâce au soutien intellectuel et financier de la Chaire, les étudiants ont bien progressé : un étudiant de doctorat a soutenu sa thèse, et cinq étudiants de maitrise ont terminé leur mémoire.

Grâce à l'expertise de la Chaire en matière de patrimoine immatériel, le titulaire a été sollicité pour participer à une quinzaine de séminaires et de colloques internationaux.

LAURIER TURGEON

\section{Chaire de recherche du Canada en patrimoine religieux bâti}

École d'architecture, bureau 3235

Université Laval

Québec (Québec) G1K 7P4
Téléphone : (418) 656-2131, p.2052

Télécopieur : (418) 656-2785

Courriel : Tania.Martin@arc.ulaval.ca

Toile : www.crcprb.chaire.ulaval.ca

\section{Présentation}

Créée en 2005, la Chaire de recherche du Canada en patrimoine religieux bâti s'est donnée comme mandat d'améliorer la compréhension de la création et de l'évolution de l'environnement bâti et des paysages culturels du Québec 